ASIAN JOURNAL OF MEDICAL SCIENCES

DOI:10.3126/ajms.v1i1.2928

\title{
The Impact of Mass Media in Using Contraceptives among Married Males-A study from Hatiya VDC of
}

\section{Makawanpur, Nepal}

Srijana Pandey ${ }^{\mathrm{a}^{*}}$ and Supendra Karki ${ }^{\mathrm{b}}$

${ }^{a}$ Department of Community Medicine, KIST Medical College, Imadol, Lalitpur, Nepal

${ }^{b}$ Hetauda School of Management and Social Sciences, Hetauda, Nepal

Abstract

Objectives: To analyze the association between exposure to mass media and use of contraceptive.

Methods: In this cross sectional descriptive study, 387 married males of Hatiya VDC were randomly selected. This study uses semi-structured questionnaire to acquire information regarding background character of respondents and the exposure of family planning message to mass media.

Results: Both print and electronic media were found major reproductive health information dissemination tools. Exposure was positively related to age, education level, income, partner approval and discussed family planning with partner. There was no significant difference in exposure based on number of living children.

Conclusion: Findings from this study are consistent with the interpretation that mass media promotion of the family planning message motivated sexual partners to discuss use of the contraceptives, and that discussion exerted a strong influence on their intention to use it. The programmatic implications of these findings are that multiple media channels should continue to be used to promote family planning and other reproductive health issues. Priority should be given to media channels that reach large numbers of the intended audience, but supporting channels (such as print and interpersonal communication) should also be included in the media mix.

Key words: Mass media, Contraceptives

\section{Introduction}

In most societies at present and recent past, men have been considered to dominate the family decision, including the decision to use contraceptives. However, men have long been neglected as a potential user of contraceptives. In spite of tremendous achievement in the use of contraceptive among Nepalese people, male involvement is only 10.2 percent against a total of 40.69 percent. ${ }^{1}$ This shows that large number of male partner yet not motivated to adopt contraceptive methods in practical life. The need and importance of promoting male contraceptive methods as well as the responsibility of male in sharing burden of contraception are now being advocated.

Boarding contraceptive methods for men to promote the male participation and their responsibilities is a priority area for the services delivery program and for contraceptive research and development activities. Mass media plays a vital role in disseminating the message to the population. Mass media have been used in social marketing programs designed to disseminate message of family planning. Family planning communications publicity has been shown to increase contraceptive use, but it remains unclear whether exposure to messages about contraception through multiple media sources has a greater impact than exposure through one medium. More information is needed about the effectiveness of these action and the mechanisms through which they influence behavior.

This study tries to seek to determine whether people's recent exposure to family planning messages in the media, as measured by their recall of these messages, has any effect on their current contraceptive use, spousal approval of family planning, discussions with their spouse about family planning or visits to a family planning service site

The main objective of the study was to analyze the association between exposure to mass media and use of contraceptive. This study also aims to find out socio-demographic characteristics of the respondents and examines the association between demographic characteristics and exposure to media messages about family planning.

\section{Materials and Methods}

This is a cross sectional descriptive study conducted in Hatiya VDC of Makawanpur. By using the formula $\mathrm{n}=\mathrm{Z} 2 \mathrm{pq} / \mathrm{d} 2$, the sample size was determined. Three hundred and eighty seven (387) married male, whose wives are in reproductive age (15-49 yrs), were purposively selected and interviewed through semi-structured questionnaire.

As the sample size was 387 and the selected village has nine wards, 43 samples from each ward were taken. Background variables like age, religion, occupation, total monthly income, number of children, education level of the respondents and his wife that are often associated with contraceptive behavior and media habits were used in the analysis. Respondents were asked whether they had heard, seen or read any family planning messages in any media channels-electronic media like radio/ television and print media like news paper/poster/pamphlets/wall chart.

\section{*Corresponding Autho}

Srijana Pandey, Associate Professor, Department of Community Medicine, KIST Medical College, Imadol, Lalitpur, Nepal, Phone Number: 977-1-5-201680 (Office); E. Mail Address: sirupandey@gmail.com
All the data collected from the fieldwork were coded, entered into SPSS database and then analyzed by SPSS 13.0. Results were obtained by the frequency distribution and cross tabulation of the variables. Cross-tabulation and association were determined using chi-square test.

\section{Results}

Three hundreds and eighty-seven married men were interviewed to find out the impact of mass media in using contraceptives.

\subsection{Socio-demographic Characteristics}

Most common socio-demographic characteristics such as age, caste, religion, educational status occupation, income, number of live children are enumerated in table no 1 .

The age of the respondents varies from 21 to 49 years. Majority of the respondent $(50.9 \%)$ were between the ages of the 31 to 40 years. The mean age of the study population is 33.48 years with standard deviation 6.164 . Majority of the respondents i.e., $87 \%$ follow Hindu religion, $54.3 \%$ had passed the SLC and above, $51.7 \%$ were farmer, $45 \%$ respondents had less than the Rs. 2000 income per month and 53.5\% have less than two children.

Among the contraceptive users, $50 \%$ of respondents between $31-40$ years age group, $83.9 \%$ Hindus were currently using contraceptive. Most of the respondents who were engaged in private jobs were using contraceptive followed by government employee. In this study, it is found that $53.6 \%$ of the respondents having monthly income more than Rs.4000, 89.3\% of respondents who passed school leaving certificate (SLC) and had formal education were currently using contraceptives. Among the respondents having less than two children, $53.6 \%$ were using the contraceptive methods and $32.1 \%$ amongst those having 3-4 children but the association between use of contraceptive and number of live children was not significant (Table 1).

\subsection{Exposure to Media Sources of Family Planning Messages}

The electronic media, such as radio and television were found important for communicating message about family planning. Majority of the respondents i.e., $90.2 \%$ were exposed to electronic media where as $64.3 \%$ of the respondents were exposed to print media.

Respondents were asked if they had heard a message about family panning message in the mass media. Especially, in this study area electronic mass media such as the radio and television was the most widespread source of family planning information, reaching $90.2 \%$ of respondents. Roughly half of those identify radio as a source of family planning messages. Almost as many respondents $(33.1 \%)$ reported seeing family planning messages in newspapers $26.4 \%$ expose to poster, pamphlets and $53.2 \%$ of the respondents were exposed to wall chart (Table 2).

\subsection{Relationship of Mass Media and Use of Contraceptive}

Contraceptive knowledge and use were closely associated with exposure to media messages about family planning. Of those respondents who recalled family planning messages in the media, nearly all $(91 \%)$ had heard of at least one modern contraceptive method. In contrast, only $61 \%$ of the respondent who could not recall any such messages had heard of any modern method (Table 3). Similarly, current use of modern methods was far greater among respondent who recalled family planning messages than among those who did not. 
Table 1: Socio-demographic Variables and Current Use of Contraceptive Methods

\begin{tabular}{|c|c|c|c|c|c|c|}
\hline \multirow{3}{*}{$\begin{array}{l}\text { Socio- } \\
\text { demographic } \\
\text { Variables }\end{array}$} & \multirow{2}{*}{\multicolumn{2}{|c|}{$\begin{array}{l}\text { Total } \\
(\mathbf{N}=387)\end{array}$}} & \multicolumn{4}{|c|}{ Current Use of Contraceptives } \\
\hline & & & \multicolumn{2}{|c|}{$\begin{array}{l}\text { Current Users } \\
(\mathrm{N}=56)\end{array}$} & \multicolumn{2}{|c|}{ Non Users $(\mathbf{N}=\mathbf{3 3 1})$} \\
\hline & $\mathbf{N}$ & $\%$ & $\mathbf{N}$ & $\%$ & $\mathbf{N}$ & $\%$ \\
\hline \multicolumn{5}{|c|}{ Age $\quad$ Mean age 33.48, SD $\quad 6.164$} & \multicolumn{2}{|c|}{ (p Value: 0.043 ) } \\
\hline $21-30 \mathrm{yrs}$ & 127 & 32.8 & 13 & 23.2 & 114 & 34.4 \\
\hline $31-40 \mathrm{yrs}$ & 197 & 50.9 & 28 & 50.0 & 169 & 51.1 \\
\hline $41-49 y \mathrm{yrs}$ & 63 & 16.3 & 15 & 26.8 & 48 & 14.5 \\
\hline \multicolumn{5}{|l|}{ Religion } & \multicolumn{2}{|c|}{ (p Value: 0.0447) } \\
\hline Hindu & 337 & 87.1 & 47 & 83.9 & 290 & 87.6 \\
\hline Others & 50 & 12.9 & 9 & 16.1 & 41 & 12.4 \\
\hline \multicolumn{5}{|l|}{ Education } & \multicolumn{2}{|c|}{ (p Value: 0.0001) } \\
\hline Illiterate & 83 & 21.4 & 2 & 3.6 & 81 & 24.5 \\
\hline Literate & 94 & 24.3 & 4 & 7.1 & 90 & 27.2 \\
\hline SLC\& above & 210 & 54.3 & 50 & 89.3 & 160 & 48.3 \\
\hline \multicolumn{5}{|c|}{ Education of the respondent wife } & \multicolumn{2}{|c|}{ (p Value: 0.0001$)$} \\
\hline Illiterate & 129 & 33.3 & 6 & 10.7 & 123 & 37.2 \\
\hline Literate & 227 & 58.7 & 34 & 60.7 & 193 & 58.3 \\
\hline SLC\& above & 31 & 8.0 & 16 & 28.6 & 15 & 4.5 \\
\hline \multicolumn{5}{|l|}{ Occupation } & \multicolumn{2}{|c|}{ (p Value: 0.001) } \\
\hline Gov. Employee & 71 & 18.3 & 20 & 35.7 & 51 & 15.4 \\
\hline Farmer & 200 & 51.7 & 6 & 10.7 & 194 & 58.6 \\
\hline Private Job & 116 & 30 & 30 & 53.6 & 86 & 26.0 \\
\hline \multicolumn{5}{|c|}{ Family income Mean income 2761.24} & \multicolumn{2}{|c|}{ (p Value: 0.0001$)$} \\
\hline$\leq$ Rs. 2000 & 174 & 45.0 & 2 & 3.6 & 172 & 52.0 \\
\hline Rs.2001-3000 & 106 & 27.4 & 3 & 5.4 & 103 & 31.1 \\
\hline Rs.3001-4000 & 60 & 15.5 & 21 & 37.5 & 39 & 11.8 \\
\hline$>$ Rs.4000 & 47 & 12.1 & 30 & 53.6 & 17 & 5.1 \\
\hline \multicolumn{5}{|c|}{ Number of living children } & \multicolumn{2}{|c|}{ (p Value: 0.477) } \\
\hline$\leq 2$ children & 207 & 53.5 & 30 & 53.6 & 177 & 53.5 \\
\hline 3-4 children & 141 & 36.4 & 18 & 32.1 & 123 & 37.2 \\
\hline $5-6$ children & 39 & 10.1 & 8 & 14.3 & 31 & 9.4 \\
\hline
\end{tabular}

Table: 2. Percentage of Respondents Who Reported Media Exposure to Family Planning Messages, by Media Type

\begin{tabular}{|l|l|l|}
\hline Exposure to mass media & $\begin{array}{l}\text { Frequency (n } \\
\text { 387) } *\end{array}$ & Percent \\
\hline Electronic media & 349 & \\
Radio/T.V. & & 90.2 \\
Print media & 249 & 64.3 \\
News paper & 128 & 33.1 \\
Poster/pamphlets & 102 & 26.4 \\
Wall chart & 206 & 53.2 \\
\hline
\end{tabular}

*Multiple responses

Among the respondents who were the exposed to Mass (electronic and print) media $89.3 \%$ using the contraceptive similarly, $8.9 \%$ were using the contraceptive methods but they were exposed only to print media. Among the respondents who were exposed to only electronic media $1.8 \%$ was using contraceptive methods.

Media exposure varied according to a variety of demographic characteristics (Table 4). Exposure was positively related to age, education level, and income. The respondents who recalled family planning messages in the media were also more likely to have discussed family planning with their partner. There was no significant difference in exposure based on number of living children.

\section{Discussion}

Many studies identified socio-demographic and other variables associated with male contraceptive use. Age, education, place of residence, number of living children and being counseled for family planning were identified as key factors determining contraceptive knowledge and use among married men in the study areas. ${ }^{2-4}$

Out of 387 respondents, only $56(14.5 \%)$ respondents were using condoms and vasectomy for contraception in practical life, which is little far from the Nepal Demographic and Health Survey, 2002. ${ }^{5}$ Almost half of the respondents between 31-40 years age group were currently using any contraceptive method. The chi square test showed significance $(p<0.05)$ between age of respondents and use of contraception.

Educational status was positively associated with higher awareness, favorable attitude and practice of family planning. ${ }^{2,6}$ It is found that uses of contraceptive method rise along with the educational status of the respondents which was similar to the study from Nigeria. ${ }^{3}$ Chi-square test signifies the relationship between education and use of contraceptive $(p<0.01)$. Similarly, there is significant $(p<0.001)$ relationship between the educational attainment of respondents wife and use of contraceptive.

Table 4: Percentage of Respondents Who Recalled Exposure to Media Messages about Family Planning by Demographic Characteristics

\begin{tabular}{|c|c|c|c|c|}
\hline \multirow[t]{2}{*}{ Contraceptive } & \multirow[t]{2}{*}{ Total } & \multicolumn{3}{|c|}{ Exposed to media messages } \\
\hline & & \multicolumn{2}{|l|}{ Yes } & No \\
\hline Know any method & 79.3 & \multicolumn{2}{|l|}{91.4} & 64.8 \\
\hline Modern & 77.7 & \multicolumn{2}{|l|}{91.1} & 61.4 \\
\hline Traditional & 45.6 & \multicolumn{2}{|l|}{58.5} & 30.0 \\
\hline $\begin{array}{l}\text { Currently use any } \\
\text { method }\end{array}$ & 17.6 & \multicolumn{2}{|l|}{25.4} & 8.2 \\
\hline Modern & 11.2 & \multicolumn{2}{|l|}{17.6} & 3.4 \\
\hline Traditional & 6.4 & \multicolumn{2}{|l|}{7.8} & 4.8 \\
\hline Mass media & \multicolumn{3}{|c|}{$\begin{array}{l}\text { Current use of contracep- } \\
\text { tive method }\end{array}$} & p value \\
\hline \multirow[b]{2}{*}{$\begin{array}{l}\text { Electronic media } \\
\text { Print media } \\
\text { Mass (both) media }\end{array}$} & Yes & No & Total & \multirow[b]{2}{*}{0.0001} \\
\hline & $\begin{array}{l}1.8 \\
8.9 \\
89.3\end{array}$ & $\begin{array}{l}29.9 \\
10 \\
60.1\end{array}$ & $\begin{array}{l}25.8 \\
9.8 \\
64.3\end{array}$ & \\
\hline
\end{tabular}

Table 3: Percentage of Respondent Who Know of a Contraceptive and Who are Currently Using a Method, by Type of Method, According to Their Exposure to Media Messages about Family Planning

\begin{tabular}{|c|c|c|}
\hline \multirow[t]{2}{*}{ Demographic Characteristic } & \multicolumn{2}{|c|}{ Exposure to Media Messages } \\
\hline & Yes & No \\
\hline Age & \multicolumn{2}{|c|}{ (p Value: $<0.001)$} \\
\hline $21-30$ & $101(79.5 \%)$ & $26(20.5 \%)$ \\
\hline $31-40$ & $109(55.3 \%)$ & $88(44.7 \%)$ \\
\hline $41-49$ & $27(42.9 \%)$ & $36(57.1 \%)$ \\
\hline Education & \multicolumn{2}{|c|}{ (p Value: $<0.001$ ) } \\
\hline Illiterate & $26(31.3 \%)$ & $57(68.7 \%)$ \\
\hline Literate & $45(47.9 \%)$ & $49(52.1 \%)$ \\
\hline SLC and above & $159(75.7 \%)$ & $51(24.3 \%)$ \\
\hline Income & \multicolumn{2}{|c|}{ (p Value: 0.002 ) } \\
\hline$\leq$ Rs. 2000 & $99(56.9 \%)$ & $75(43.1 \%)$ \\
\hline Rs.2001-3000 & $73(68.9 \%)$ & $33(31.1 \%)$ \\
\hline Rs.3001-4000 & $47(78.3 \%)$ & $13(21.7 \%)$ \\
\hline$>$ Rs. 4000 & $37(78.7 \%)$ & $10(21.3 \%)$ \\
\hline \multicolumn{2}{|l|}{ Number of live children } & (p Value: 0.25 ) \\
\hline$\leq 2$ children & $119(57.5 \%)$ & $88(42.5 \%)$ \\
\hline 3-4 children & $71(50.4 \%)$ & $70(49.6 \%)$ \\
\hline $5-6$ children & $18(46.2 \%)$ & $21(53.8 \%)$ \\
\hline \multicolumn{2}{|l|}{ Partner approval } & (p Value: <0.001) \\
\hline Yes & $51(91.1 \%)$ & $5(8.9 \%)$ \\
\hline No & $143(43.2 \%)$ & $188(56.8 \%)$ \\
\hline \multicolumn{3}{|c|}{ Discussed family planning with partner $\quad(p$ Value: $<0.001)$} \\
\hline Yes & $148(74.0 \%)$ & $52(26.0 \%)$ \\
\hline No & $93(49.7 \%)$ & $94(50.3 \%)$ \\
\hline
\end{tabular}

Actual use of contraceptives varied considerably across occupations. Among the working class, prevalence is low, especially within marriage. This study shows wide variation in contraceptive uses across occupational line which is similar to the other studies. ${ }^{7}$ The chi-square test $(\mathrm{p}<0.001)$ is indicating that there is strong relationship between the occupation and the use of contraception.

This study also shows the strong relationship $(\mathrm{p}<0.001)$ between poverty and use of contraceptive. Similar strong link between use of contraceptives and level of economic status were observed by Mungai. ${ }^{6}$

The respondents who have higher number of children are less likely to use any method of contraceptives compared to the respondents with fewer number of children. The chi-square test $(p>0.05)$ suggests that there is no significant difference between user of contraceptive and number of children.

In developing countries, many analyses of cross sectional surveys have shown strong associations between exposure to mass media and contraceptive use $^{8-12}$ In this study the chi-square test result $(\mathfrak{p}<0.001)$ indicate that there is association between mass media and use of contraceptive methods. Similar study by Piotrow et. al. ${ }^{13}$ mentioned that exposed to mass media has increased the use of contraception in Zimbabwe. Both print and electronic media are vital reproductive health information dissemination tools. ${ }^{6}$ 
The more types of media that a man or women are exposed to, the more likely they are to practice contraception. Recent research based on nationally representative surveys confirms a strong association between exposure to family planning messages in the mass media and contraceptive use which is also similar to this study. The significant relationship persisted even after differences in age, residence and socioeconomic status were taken into account. ${ }^{8}$

Diffusion theorists postulate that mass media affects contraceptive use by stimulating the discussion of contraceptive use between partners. ${ }^{14}$ Studies show that informal personal appeals have a very strong effect. ${ }^{15}$ Through sharing information and mutual feedback, people give meaning to information, understand each other's views, and influence each other ${ }^{16}$ Several studies have shown that discussion of contraceptive use with a partner is highly predictive of future contraceptive adoption. ${ }^{12,14}$ Mass media exposure significantly increased the likelihood that a man or a woman would discuss use of the contraceptives with a partner. This study also supports the result of the study by Jato et.al. ${ }^{12}$

\section{Conclusion}

By reviewing the study findings it can be concluded that almost all respondents know about at least one of contraceptive methods and exposure to mass media had significant association. This study found that respondents exposure to media sources of family planning messages was associated with increased contraceptive use, especially that of modern methods. For example, only $3 \%$ of respondents who had not been exposed to any family planning messages in the media were using modern methods, compared with $18 \%$ of those who had been exposed to at least one media source of family planning information.

\section{References}

1. Annual Report, Department of Health Services, 2003/2004, Ministry of Health, Department of Health Service, Katmandu, 2004

2. Ismail S, Med J. Men's Knowledge, Attitude and Practices of Family Planning in North Gondar. Ethiop Med J 1998; 36(4):261-71. PMID: 11957302

3. Lawoyin TO, Osinowo $\mathrm{H}$, Babatunde $\mathrm{M}$, Bajomo TG, Betiku AO Biakolo, Busari KT, Fehintola. A Family Planning In Rural Nigeria: A Study among Men. Afr J Med and Med Sci 2002; 31(2):159-62.

4. Oyediran KA, Ishola GP, Feyisetan BJ. Factors Affecting Ever-Married Men's Contraceptive Knowledge and Use in Nigeria. Department of Sociology, University of Ibadan, Nigeria, 2002; 34(4):497-510.

5. NDHS. Nepal Demographic and Health Survey 2006: Key Findings. Ministry of Health and Population, New ERA and Macro International Inc, Kathmandu, Nepal, 2007:5-6.

6. Mungai P. Men's Knowledge, Attitudes and Practices with Regard to Family Planning. Afr. Link; 1996:Apr 5-7; PMID: 12292587 Pub med. Available at www.ncbi.nlm.nih.gov/pubmed/12292587.

7. Posner JK, Mbodji F. Men's Attitudes about Family Planning in Dakar, Senegal. International Family Planning Perspectives 1989; 21(3):279-91.

8. Westoff CF, Rodriguez G. The Mass Media and Family Planning in Kenya, International Family Planning Perspectives 1995; 21(1):26-31 \& 36.

9. Kincaid DL, Merritt AP, Nickerson L, Buffington SC, De Castro MPP, De Castro BM. Impact of a Mass Media Vasectomy Promotion Campaign in Brazil. International Family Planning Perspectives 1996; 22(4): 169-175.doi:10.2307/2950815.

10. Kim YM, Marangwanda C. Stimulating Men's Support for Long-term Contraception: A Campaign in Zimbabwe. Journal of Health Communication 1997; 2: 271-297.doi:10.1080/108107397127590.

11. Kane TT, Gueye M, Speizer I, Pacque-Margolis S, Baron D. The Impact of a Family Planning Multimedia Campaign in Bamako, Mali. Studies in Family Planning 1998; 29(3): 309-323.doi:10.2307/172277 PMid:9789324.

12. Jato MN, Simbakalia C, Tarasevich JM, Awasum DN, Kihinga CNB, Ngirwamungu E. The Impact of a Multimedia Family Planning Promotion on the Contraceptive Behavior of Women in Tanzania. International Family Planning Perspectives 1999; 25(2): 60-67. doi:10.2307/2991943.

13. Piotrow PT, Kincaid DL, Hindin MJ, Lettenmaier CL, Kuseka I, Silberman T, Zinanga A,Chikara F, Adamchak DJ, Mbizvo MT, et. al. Changing Men's Attitudes and Behavior: The Zimbabwe Male Motivation Project. Center for Communication Programs 1992 ; 23(6Pt1): 365-

14. Rogers EM, Vaughan PW, Swalehe RMA, Rao N, Svenkerud P and Sood S. A Radio Soap Opera's Effects on Family Planning Behavior in Tanzanai. Studies in Family Planning 1999; 30(3): 193-211.doi:10.1111/ j.1728-4465.1999.00193.x PMid:10546311.

15. Klapper JT. The Effects of Mass Communication, New York: Free Press, 1969.

16. Bandura A. Social Foundations of Thought and Action. A Social Cognitive Theory, New Jersey: Prentice Hall, 1986. 